\title{
Severe myositis ossificans in a paraplegic trauma patient: Influence in pressure sore management
}

\author{
Wendy Lynne Parker MD PhD ${ }^{1}$, Jacqueline C Hodge MD², Marie-Lucie Lessard MD FRCSC FRCSC FACS ${ }^{3}$
}

\begin{abstract}
WL Parker, JC Hodge, M-L Lessard. Severe myositis ossificans in a paraplegic trauma patient: Influence in pressure sore management. Can J Plast Surg 2004;12(4):205-209.

Myositis ossificans $(\mathrm{MO})$ is a benign, progressive, ossifying lesion that displays a characteristic zonal histological appearance. MO traumatica is a localized form of heterotopic bone formation, associated with repetitive micro- and/or macrotrauma in the majority of cases. The importance of imaging to differentiate $\mathrm{MO}$ from sarcomatous change and to determine maturity of the lesion is identified because suboptimal operative intervention on immature $\mathrm{MO}$ inevitably results in recurrence. A severe case of $\mathrm{MO}$ in a 24-year-old paraplegic man with chronic bilateral greater trochanteric pressure sores is presented, and the importance of the $\mathrm{MO}$ in the etiology and treatment of this case is discussed. An extensive review of the literature is included and integrated.
\end{abstract}

\section{Myosite ossifiante sévère chez un polytraumatisé paraplégique : Influence du traitement des escarres de décubitus}

La myosite ossifiante $(\mathrm{MO})$ est une lésion progressive bénigne caractérisée par son aspect histologique circonscrit. La MO traumatique est une forme localisée de formation osseuse hétérotopique associée à un microet/ou macrotraumatisme dans la majorité des cas. L'importance de l'imagerie pour différencier la MO d'une lésion sarcomateuse et pour déterminer la maturité de la lésion est à souligner puisqu'une intervention chirurgicale stratégique suboptimale sur une $\mathrm{MO}$ immature entraîne inévitablement la récurrence. Un cas sévère de $\mathrm{MO}$ chez un paraplégique de 24 ans présentant des escarres de décubitus trochantériennes bilatérales chroniques est présenté ici. On aborde en outre l'importance de la MO dans l'étiologie et le traitement de ce cas. L'article propose aussi une revue complète de la littérature.

Key Words: Heterotopic ossification; Myositis ossificans;

Paraplegic; Pressure sore

\begin{abstract}
A 24-year-old trauma patient, paraplegic secondary to a gunshot wound at the T5 level, was referred to the Plastic Surgery Division of the McGill University Hospital Center with grade IV bilateral trochanteric pressure sores. During the investigation, the presence of severe, left-sided pelvic myositis ossificans (MO) resulting in a fixed flexion contracture of the hip was noted. The patient had severe pain and spasm on leg extension and was unable to sleep or rest in a supine position. The radiological findings were consistent with MO. It was clear that this underlying problem had to be addressed simultaneously to provide definitive treatment of the trochanteric pressure sores. A review of the literature and details of the investigation of this specific case are provided.
\end{abstract}

\section{LITERATURE REVIEW}

$\mathrm{MO}$ can be viewed as four distinct clinical entities, determined by etiology, as outlined by Steiner et al (1): MO traumatica, MO progressiva, $\mathrm{MO}$ associated with muscle immobility or degenerative change, and pseudomalignant $\mathrm{MO}$. The original description of heterotopic bone formation associated with spinal cord injury was given in 1918 by Dejerine and Gillier, who noted it in $48 \%$ of the paraplegic and quadriplegic patients they investigated (2). Now, heterotopic ossification around the hip is a well-recognized complication of spinal cord injury, the incidence of which is routinely reported to be $15 \%$ to $20 \%$ (2). Proposed theories for the development of these various forms of MO include implantation of periosteum into the muscle, escape of osteogenic cells from the periosteum, ossification of a hematoma and metaplasia of connective tissue cells (3). Men and women are equally affected, and $75 \%$ are younger than 30 years of age. MO can be classified into four clinical and radiographical stages from the onset of pain (Table 1) (4-6). Marked zonation becomes radiographically apparent as the lesion matures, and can be correlated histologically (Table 2) (6).

\section{Diagnosis and imaging}

The accurate diagnosis of this lesion is important to distinguish $\mathrm{MO}$ from sarcomatous change. Histologically, this can be confusing; therefore, relying on biopsy to make a diagnosis is not warranted. In addition, this lesion has been mistaken for hematomas, infection or abscess, benign neoplasms and primary malignant lesions such as malignant mesenchymomas or metastatic $\mathrm{MO}$ (7). On serial $\mathrm{x}$-rays following a trauma, peripheral ossification gradually develops, but may take six to eight weeks to be detectable and a differential diagnosis remains. Thus, $\mathrm{x}$-ray results should be correlated with serial nuclear scans. On computed tomography (CT) scan, MO has a characteristic welldefined shell of bone. Although CT clearly defines the location of the lesion and its extent and invasion into local tissues, CT

${ }^{1}$ Plastic Surgery Resident, McGill University, ${ }^{2}$ Department of Radiology, McGill University Health Centre; ${ }^{3}$ Division of Plastic and Reconstructive Surgery, Royal Victoria Hospital, McGill University, Montreal, Quebec

Correspondence: Dr Lucie Lessard, Division of Plastic Surgery, Montreal General Hospital, Livingston Hall Pavilion L9-317,

1650 Cedar Avenue, Montreal, Quebec H3G 1A4. Telephone 514-934-1934 ext 44341, fax 514-934-8207, e-mail lucie.lessard@muhc.mcgill.ca 
TABLE 1

Staging classification of myositis ossificans

\begin{tabular}{lccl}
\hline Stage & Maturity & \multicolumn{1}{c}{$\begin{array}{c}\text { Clinical } \\
\text { symptoms }\end{array}$} & $\begin{array}{c}\text { Radiological } \\
\text { findings }\end{array}$ \\
\hline I & Up to 3 weeks & $\begin{array}{c}\text { Fever and } \uparrow \text { ESR, mild } \\
\text { local soft tissue swelling, } \\
\text { lack of muscle stretch } \\
\text { Edema, definitive soft } \\
\text { tissue mass }\end{array}$ & None \\
II & 3 to 8 weeks & Early calcification \\
III & 8 to 12 weeks & $\begin{array}{c}\text { Firm mobile mass, } \\
\text { often nontender }\end{array}$ & $\begin{array}{c}\text { Marked peripheral } \\
\text { calcification }\end{array}$ \\
IV & 12 weeks to & $\begin{array}{c}\text { Possible shrinkage } \\
\text { of lesion }\end{array}$ & $\begin{array}{c}\text { Zonation to } \\
\text { variable findings }\end{array}$ \\
\hline
\end{tabular}

$\uparrow E S R$ Increased erythrocyte sedimentation rate

should be reserved for the evaluation of mature lesions because it is a more costly examination than nuclear imaging $(1,8)$.

Nuclear imaging, three-phase bone scans in particular, is the standard in determining lesion maturity. Active or immature $\mathrm{MO}$ lesions demonstrate increased radiotracer activity on arterial, blood pool and delayed phases. As the MO lesion matures, it becomes inactive, displaying increased activity on only the third or delayed phase of the bone scan (8). Ancillary radiological exams, most often CT, are required because of the poor spatial resolution of nuclear imaging that fails to give precise details on lesion size, demarcation and surrounding anatomical structures. Despite this drawback, no other imaging technique has been found to be superior to nuclear scanning in its ability to determine lesion maturity.

\section{Complications}

Once definitively diagnosed as $\mathrm{MO}$, heterotopic bone formation may present with complications - those directly related to the lesion and those related to the treatment of $\mathrm{MO}$. $\mathrm{MO}$ runs a relatively benign course in $80 \%$ of patients; however, the lesion itself can result in chronic severe pain and decreased range of motion of an involved joint or muscle. In the $20 \%$ of cases where significant loss of motion develops, ankylosis is noted in 10\% (9). Several cases of osteosarcoma arising within $\mathrm{MO}$ have been presented in the literature $(1,10)$. In addition, $\mathrm{MO}$ can lead to peripheral neuropathies and, in one case, brachial plexopathy (11). Although infrequently, acute fractures through preexisting, quiescent, heterotopic bone may occur (12).

Osteomyelitis has been considered both a complication of $\mathrm{MO}$ as well as a predisposing factor (2). Similarly, pressure sores may present after $\mathrm{MO}$ is established or incite the lesion $(2,13)$. Moreover, early aggressive operative resection of the lesion ultimately results in recurrence and, often, progression of $\mathrm{MO}$.

The following case report concerns a paraplegic patient with a severe $\mathrm{MO}$ of the left hip being the main etiology of bilateral grade IV trochanteric pressure sores.

\section{CASE PRESENTATION}

A 22-year-old man sustained a gunshot wound to the chest, resulting in complete T5 paraplegia. Over the next five years, he had repeated admissions for urosepsis and bilateral osteomyelitis of the hips and was treated with various antibiotic regimens. His condition progressed such that he developed severe flexion contractures of the hips, and ultimately, chronic
TABLE 2

Zonation phenomenon of myositis ossificans correlated with histology

\begin{tabular}{lll}
\hline Zone & Location & Histological findings \\
\hline I & Central & Mitotic activity present, \\
& highly cellular, \\
& & variable cell size and shape \\
II & Intermediate & Immature osteoma \\
III & Peripheral & Mature bone with collagenous \\
& & fibrous stroma \\
\hline
\end{tabular}

bilateral greater trochanteric pressure sores that were unresponsive to medical treatment (Figure 1). He was referred to our service for management. His work-up included standard $\mathrm{x}$-rays (Figure 2A), CT (Figure 2B) and nuclear medicine scans (Figure 3), which resulted in a diagnosis of $\mathrm{MO}$.

Despite this patient's chronic pain and immobility, surgical treatment was avoided throughout the period of $\mathrm{MO}$ immaturity (Figure 2A). It is well accepted that operative intervention at this time leads to recurrence or progression of the lesion. It is likely that this patient's trochanteric pressure sores were a result of the vicious cycle of inappropriate supine and wheelchair positioning secondary to the hip flexion contracture from the underlying $\mathrm{MO}$.

Once lesion maturity was reached, as documented by nuclear scan (Figure 3D), the $\mathrm{MO}$ was surgically resected. Bilateral proximal femorectomy was performed at two independent operative interventions. Initially, the patient was positioned in a left lateral decubitus position and the left hip was approached in the standard fashion for a total hip arthroplasty. Dissection was carried out over the left femur, and the greater trochanter was identified. Of note, an extensive bursa had formed, underlying the site of the chronic ulcer. There was significant heterotopic ossification surrounding primarily the anterior and medial aspects of the femur. The femur was divided at the level just cephalad to the lesser trochanter and disarticulated from the pelvis (Figure 4A). This allowed for better exposure of the medial and anterior $\mathrm{MO}$, which was subsequently resected (Figure 4B). An inferolaterally based gluteus maximus pedicled muscle flap was advanced into the left acetabulum and bony defect (Figure 4C), hemostasis was achieved and three drains were left in situ. The indurated soft tissue surrounding the ulcer was saucerized and the wound was closed primarily (Figure 4D). The patient tolerated the procedure well, and there were no postoperative complications. Postoperatively, the patient was given supplemental magnesium as recommended and was continued on nonsteroidal antiinflammatory drugs (NSAIDs) until leaving the hospital. A similar procedure was subsequently performed on the right hip, but closure was performed with a right vastus lateralis advancement flap. He was without recurrent trochanteric pressure sores up to two years postsurgery.

This case of a paraplegic patient with bilateral trochanteric pressure sores associated with and subsequent to severe hip flexion contracture was challenging. The severe ankylosis of the left hip contributed to his pressure sores because positioning was limited to the right and left lateral decubitus. Supine positioning resulted in extreme discomfort due to the bilateral hip contractures. This fixed flexed position of his hip was 


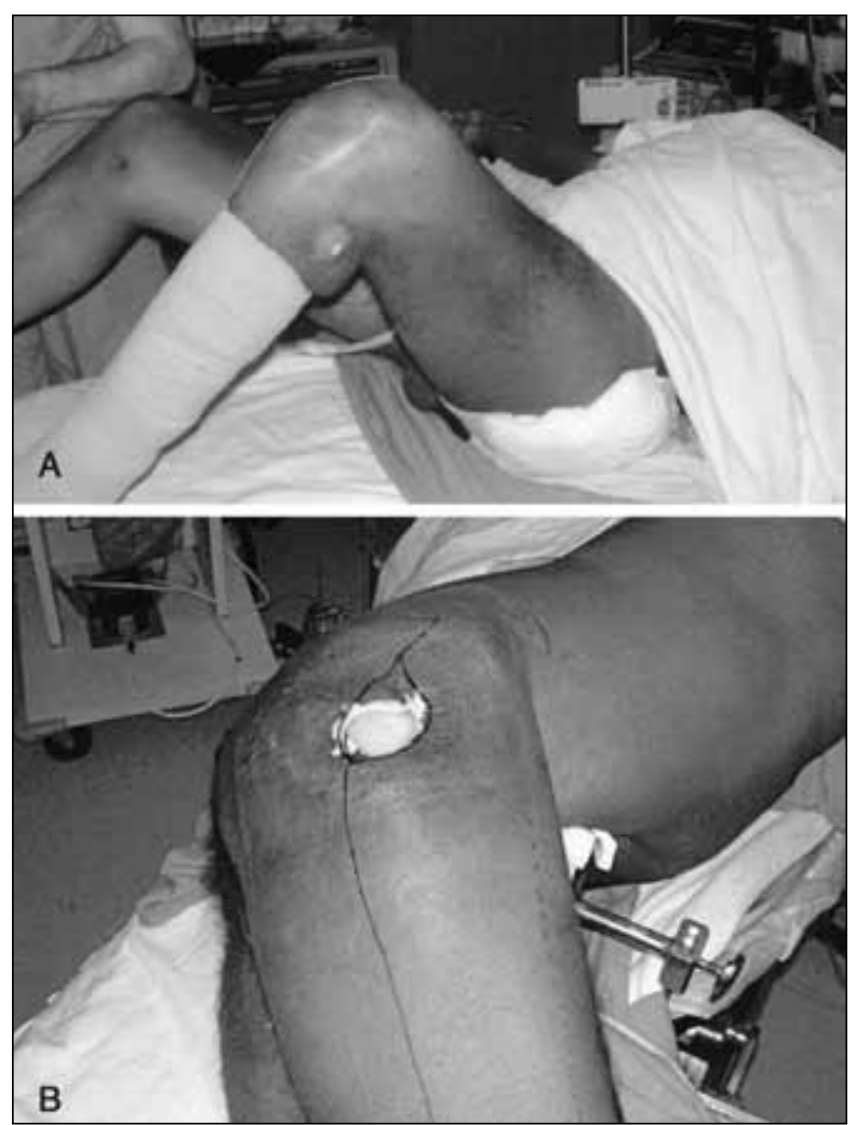

Figure 1) A In the supine position, the patient demonstrates severe flexion contractures of both hips. $\mathbf{B}$ With the patient in the right lateral decubitus position, the right greater trochanteric pressure sore is evident

attributable to the peripelvic MO. This was confirmed by our investigations and the pathological specimen.

\section{DISCUSSION}

Although diagnosis of early MO can be difficult, if it is made, some authors advocate rest, elevation and ice for the affected soft tissue $(14,15)$. However, there has been increased focus on the treatment of more mature lesions, with approaches based on bone physiology and inhibition of hydroxyapatite (HA) formation (16).

One approach has been the use of diphosphonates. However, absorption of diphosphonates is limited; only $1 \%$ to $10 \%$ is absorbed when administered orally, and a maximum of $50 \%$ is absorbed when administered intravenously (17). Moreover, these agents only delay the development of MO, with mineralization ensuing once treatment is withdrawn (18). Magnesium has been shown to inhibit HA formation by adsorbing onto the crystal surfaces and blocking growth sites and, thus, has been used to inhibit heterotopic bone formation with a $75 \%$ success rate noted (19). Proteoglycans, aluminum ions, metal citrate complexes, phosphoproteins and serum proteins such as albumin and other globulins have also been shown to inhibit HA formation in vitro, but this is not supported by any clinical trials (16).

NSAIDs, such as indomethacin and ibuprofen, have been shown to decrease the formation of $\mathrm{MO}$ and are considered to be prophylactic agents. A review of 12 randomized clinical trials
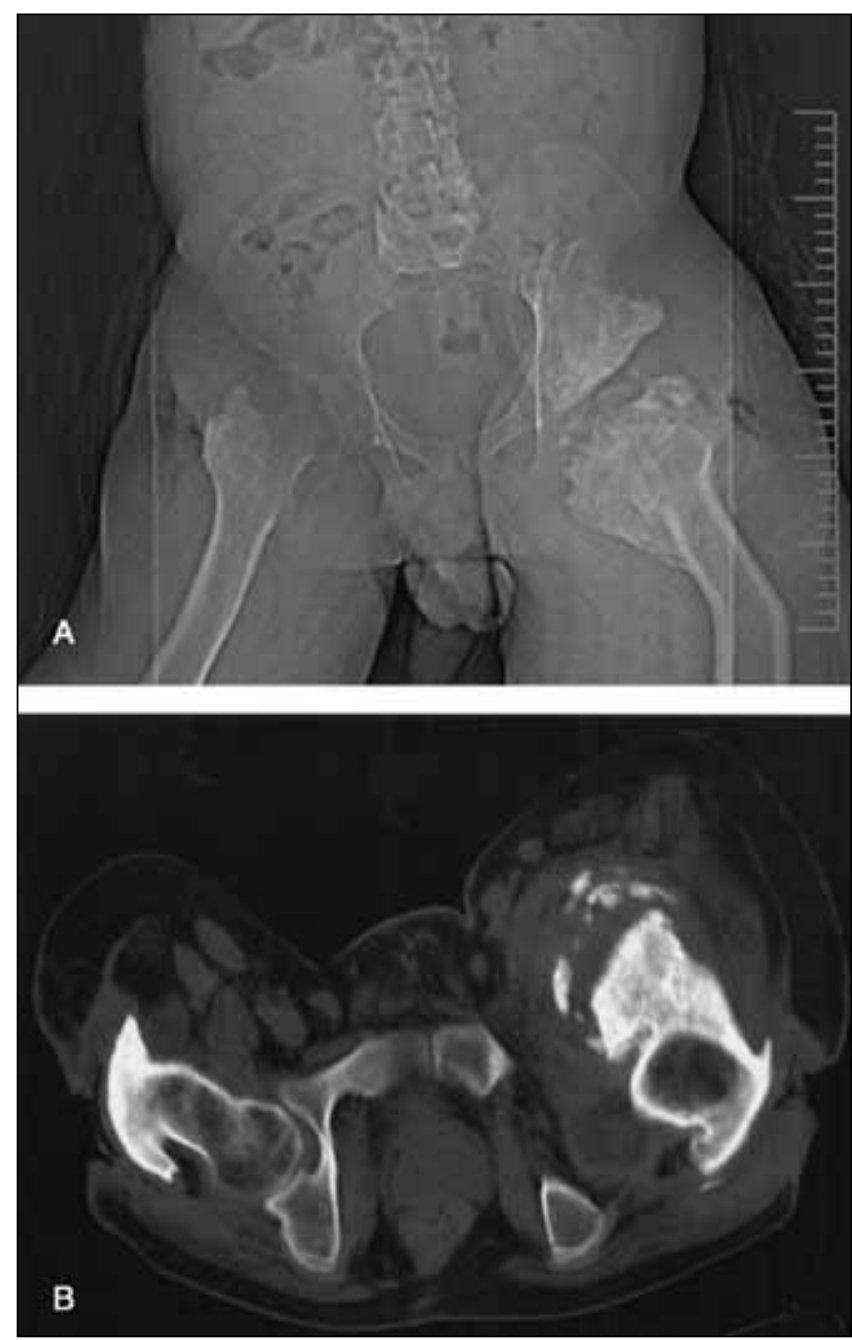

Figure 2) A Anteroposterior radiograph of the pelvis. The small curvilinear collections of gas bilaterally represent soft tissue ulcers. Exuberant myositis ossificans (MO) explains the relatively increased density and size of the left acetabular/supra-acetabular and left proximal femoral shaft region. The MO partially obscures the left hip joint. A small area of $\mathrm{MO}$ is contiguous with the right greater trochanter. B Transaxial computed tomography scan through the hips. A small curvilinear rim of $\mathrm{MO}$ lies adjacent to the right greater trochanter. A $2 \mathrm{~cm} \times 1 \mathrm{~cm}$ ulcer lies superficial to the MO. At the contralateral (left) hip, a large bony and soft tissue mass sits anterior to the proximal femoral diaphysis. The soft tissue areas represent $\mathrm{MO}$ that has not yet ossified. A smaller ulcer, approximately $1 \mathrm{~cm} \times 1 \mathrm{~cm}$, is seen lateral to the peripheral extent of the MO. The pocket of fluid sitting between the left femoral shaft and left ischial tuberosity represents a hip joint effusion. There is no osteolysis or periosteitis at either femora/MO to suggest superimposed osteomyelitis

concluded that medium- to high-dose NSAIDs decrease the risk of heterotopic bone formation by $62 \%$ following total hip arthroplasty (20).

Local radiotherapy has also been shown to block bone induction by bone morphogenic proteins (BMPs) and therefore has been used as prophylactic treatment for MO. A prospective trial demonstrated that treatment with $200 \mathrm{rads} /$ day of radiation given over five to seven days preoperatively and for one to four days postoperatively following total hip arthroplasty was highly effective in the prevention of 


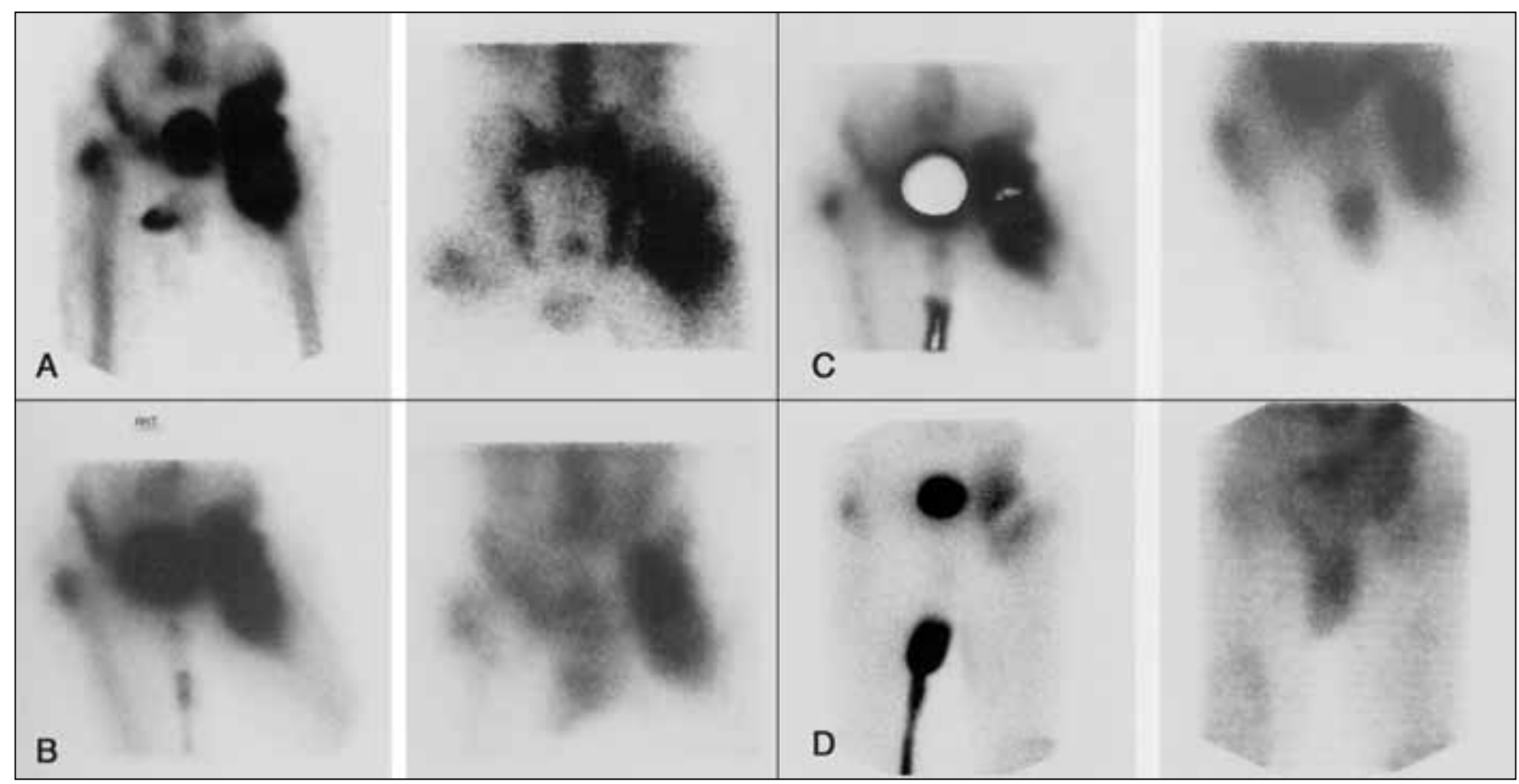

Figure 3) Nuclear medicine scans of the pelvis (bone and gallium). A Evidence of immature myositis ossificans. B and $\mathbf{C}$ Evolution of the lesion is seen by the gradual decrease in image intensity over the course of five years. D Lesion maturity is suggested by the stabilization of activity of the lesion
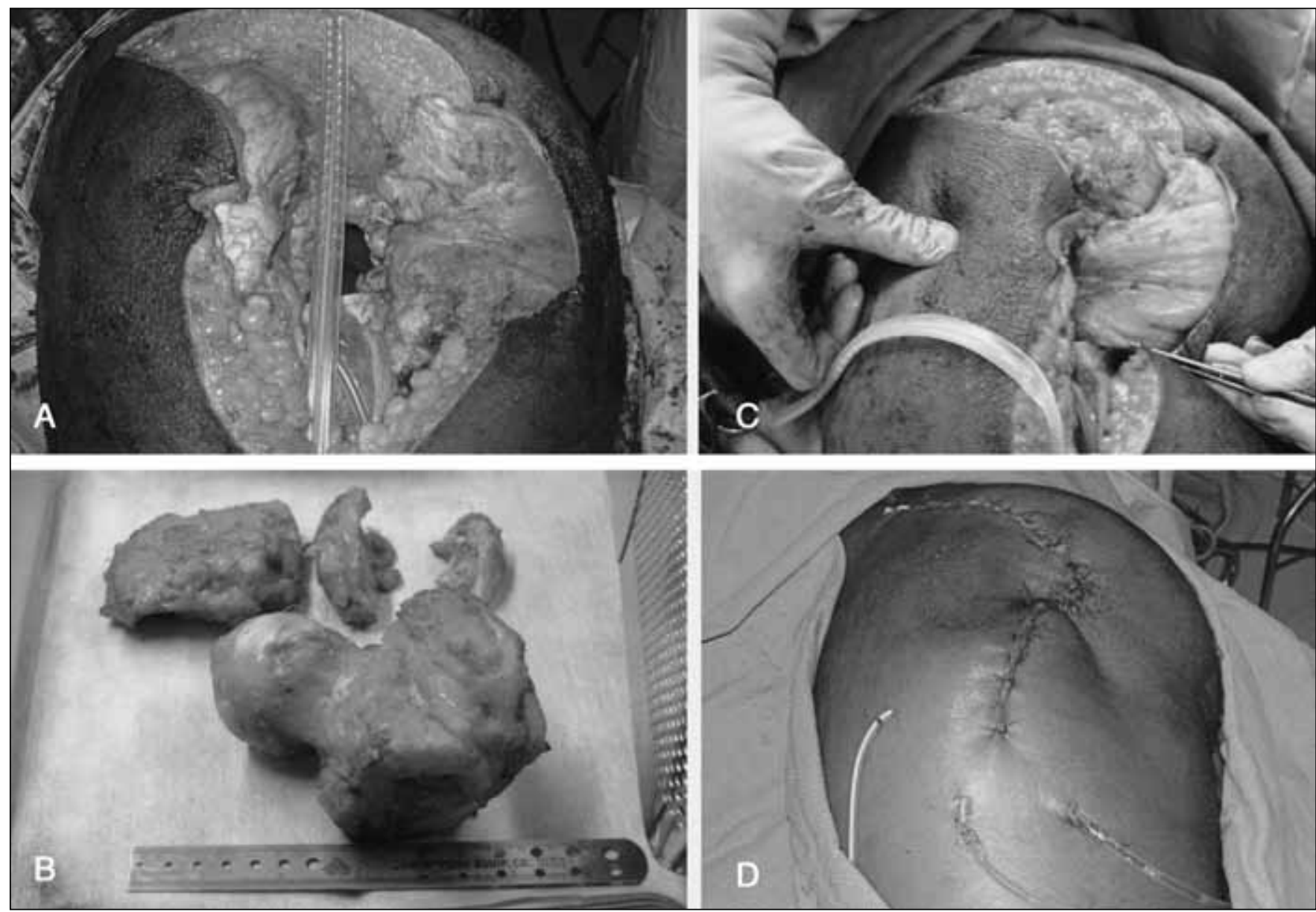

Figure 4) A The extent of the surgical defect following myositis ossificans resection. The femoral head has been disarticulated and the distal extent of the femoral resection can be seen. B Resected specimen of the left proximal femur and surrounding myositis ossificans. C Inferiorly based gluteus maximus flap rotated into the surgical defect. D Closure achieved by direct approximation over suction drains 
both heterotopic ossification and the recurrence after excision of pre-existing lesions (21). Similar results have been reported with postoperative regimens (22,23). In addition, BMPs and $\mathrm{MO}$ have also been inhibited by antibody against BMP-4 or via an antagonist noggin, which binds BMP-4 directly, inhibiting ectopic bone formation (24,25).

Operative intervention for immature $\mathrm{MO}$ is not warranted. Even for mature lesions, caution is urged and complete excision should be performed, otherwise rapid local recurrence is the rule (14). Surgical excision should be reserved for mature lesions resulting in intractable pain and severe limitation of motion. Shehab et al (9) have recently outlined criteria for recommending surgical removal of heterotopic ossification, including significantly limited range of motion for involved joint (eg, hip should have less than $50 \%$ range of motion); absence of local fever, swelling, erythema or other clinical findings of acute heterotopic ossification; normal serum alkaline phosphatase; and return of bone scan findings to normal or near normal, or a sharply decreasing trend followed by steady state for two to three months. The outcome may be further optimized by a combined medical and surgical therapeutic approach.

\section{REFERENCES}

1. Steiner M, Gould AR, Kushner GM, Lutchka B, Flint R. Myositis ossificans traumatica of the masseter muscle: Review of the literature and report of two additional cases. Oral Surg Oral Med Oral Pathol Oral Radiol Endod 1997;84:703-7.

2. Tanaka T, Rossier AB, Hassey RW, Ahnberg DS, Treves S. Quantitative assessment of para-osteo-arthropathy and its maturation on serial radionuclide bone images. Radiology 1977;123:217-21.

3. Takahashi K, Sato K. Myositis ossificans traumatica of the medial pterygoid muscle. J Oral Maxillofac Surg 1999;57:451-6.

4. Shirkhoda A, Armin AR, Bis KG, Makris J, Irwin RB, Shetty AN. MR imaging of myositis ossificans: Variable patterns at different stages. J Magn Reson Imaging 1995;5:287-92.

5. Tyler JL, Derbekyan V, Lisbona R. Early diagnosis of myositis ossificans with Tc-99m diphosphonate imaging. Clin Nucl Med 1984;9:256-8.

6. Heinrich SD, Zembo MM, MacEwen GD. Pseudomalignant myositis ossificans. Orthopedics 1989;12:599-602.

7. Massengill AD, Seeger LL, Yao L, Mirra JM, Eckardt JJ. Malignant mesenchymoma of the thigh. Skeletal Radiol 1995;24:301-4.

8. Kirkpatrick JS, Koman LA, Rovere GD. The role of ultrasound in the early diagnosis of myositis ossificans. A case report. Am J Sports Med 1987;15:179-81.

9. Shehab D, Elgazzar AH, Collier BD. Heterotopic ossification. J Nucl Med 2002;43:346-53.

10. Konishi E, Kusuzaki K, Murata H, Tsuchihashi Y, Beabout JW, Unni KK. Extraskeletal osteosarcoma arising in myositis ossificans. Skeletal Radiol 2001;30:39-43.

11. Reavey-Cantwell JF, Garonzik I, Viglione MP, McCarthy EF, Belzberg AJ. A brachial plexopathy due to myositis ossificans. Case report and review of the literature. J Neurosurg 2001;95:525-8.

12. Mestan MA, Bassano JM. Fractured heterotopic bone in myositis ossificans traumatica. J Manipulative Physiol Ther 2001;24:296-9.

13. Hassard GH. Heterotopic bone formation about the hip and unilateral decubitus ulcers in spinal cord injury. Arch Phys Med Rehabil 1975;56:355-8.

\section{CONCLUSION}

Peripelvic heterotopic ossification is well documented in patients with spinal cord injury, with an incidence reported to be as high as $15 \%$. It is essential to address the MO problem to succeed with the surgical treatment of these associated and secondary pressure sores. The clinician has two responsibilities with regard to managing the patient with MO: to avoid misdiagnosis of a sarcoma, and to determine the maturity of MO.

Imaging studies, rather than biopsy, are the key to both diagnostic work-up and timely intervention. Whereas premature surgery lends itself to inevitable recurrence of $\mathrm{MO}$, delayed intervention may result in sequelae. Moreover, it is important to remember the relatively high risk of developing $\mathrm{MO}$ in the paraplegic population. There appears to be a role for both ionizing radiation and NSAIDs in the prevention and recurrence of MO. These modalities should be considered in the plastic surgeon's armamentarium against the lesion and its potential sequelae in high risk patients, namely, spinal cord injured with spasticity, concurrent infections, pressure sores and ensuing surgical procedures.

14. King JB. Post-traumatic ectopic calcification in the muscles of athlete: A review. Br J Sports Med 1998;32:287-90.

15. Wieder DL. Treatment of traumatic myositis ossificans with acetic acid iontophoresis. Phys Ther 1992;72:133-7.

16. Blumenthal NC. Mechanisms of inhibition of calcification. Clin Orthop 1989;247:279-89.

17. Devogelaer JP. Clinical use of bisphosphonates. Curr Opin Rheumatol 1996;8:384-91.

18. Bijvoet OL, Nollen AJ, Slooff T, Feith R. Effect of a diphosphonate on para-articular ossification after total hip replacement. Acta Orthop Scand 1974;45:926-34.

19. Ditmar R, Steidl L. The importance of magnesium in orthopaedics VI. The importance of magnesium in the treatment of ectopic calcifications and ossifications. Acta Chir Orthop Traumatol Cech 1989;56:190-200.

20. Neal B, Rodgers A, Dunn L, Fransen M. Non-steroidal antiinflammatory drugs for preventing heterotopic bone formation after hip arthroplasty. Cochrane Database Syst Rev 2000;3:CD001160.

21. Ayers DC, Evarts CM, Parkinson JR. The prevention of heterotopic ossification in high-risk patients by low-dose radiation therapy after total hip arthroplasty. J Bone Joint Surg Am 1986;68:1423-30.

22. Coventry MB, Scanlon PW. The use of radiation to discourage ectopic bone: A nine-year study in surgery about the hip. J Bone Joint Surg Am 1981;63:201-8.

23. Knelles D, Barthel T, Karer A, et al. Prevention of heterotopic ossification after total hip replacement: A prospective, randomized study using acetyl salicylic acid, indomethacin and fractional single dose irradiation. J Bone Joint Surg Br 1997;79:596-602.

24. Reddi AH. Initiation of fracture repair by bone morphogenetic proteins. Clin Orthop 1998;355:S66-72.

25. Zimmerman LB, De Jesus-Escobar JM, Harland RM. The Spemann organizer signal noggin binds and inactivates bone morphogenetic protein 4. Cell 1996;86:599-606. 